BLS 34, No 1 2008. DOI: http://dx.doi.org/10.3765/bls.v34i1.3567

(published by the Berkeley Linguistics Society and the Linguistic Society of America)

\title{
Modification within a Noun Phrase in Sidaama (Sidamo) ${ }^{1}$
}

\author{
KAZUHIRO KAWACHI ${ }^{\mathrm{i}}$ and ABEBAYEHU AEMERO TEKLESELASSIE ${ }^{\mathrm{ii}}$ \\ ${ }^{\mathrm{i}}$ Research Institute for Languages and Cultures of Asia and Africa, Tokyo Univer- \\ sity of Foreign Studies, and Meiji Gakuin University \\ ${ }^{\text {ii }}$ George Washington University
}

\section{Introduction}

This study shows that the notion of modification within a noun phrase in Sidaama (Sidamo), a Cushitic language of Ethiopia, is often somewhat different from this notion as traditionally used in linguistics. In this language, although there are a few cases where modification in its ordinary sense, which is syntactic, is relevant, a grammatical distinction is made in several portions of the grammar in terms of whether or not a noun is Modified (henceforth, Modified and related words such as Unmodified, Modify, Modification, and Modifiers are capitalized for Sidaama grammar) by the possessive pronominal suffix, as well as a syntactic modifier like an adjective, a numeral, an adnominal demonstrative, an adnominal interrogative, a genitive noun phrase, and a relative clause.

The paper is organized as follows. Section 2 briefly discusses how the notion of modification is used in linguistics. Section 3 describes the ways in which Sidaama makes a distinction between Modified and Unmodified common nouns in noun phrases. Section 4 looks at constructions in other languages that appear to make distinctions in terms of modification to examine whether any of them are similar to the Modification distinction in Sidaama. Section 5 concludes the paper.

\footnotetext{
${ }^{1}$ We would like to express our sincere thanks to Matthew S. Dryer, Leonard Talmy, and Jürgen Bohnemeyer for their advice on a study on which portions of the present paper are based (Kawachi 2007). Our many thanks also go to Sileshi Workeneh, Solomon Shaamanna, and Yehualaeshet Aschenaki for being the first author's consultants during his fieldwork in the Sidaama zone in March 2008, to Abdi Hajikandi for his comments on Persian forms, and to Justin Boffemmyer and Ichiro Yuhara for their comments on portions of earlier versions of this paper. We would also wish to convey profound gratitude to the audience at BLS, especially, Bernard Comrie, Larry Hyman, and George Bergman, for their comments and discussions.

List of Abbreviations. [ACC]: Accusative (marked with the suprafix), (ACC): Accusative (not marked with the suprafix), ALL: Allative, EP: Epenthetic vowel, EZ: Ezafe suffix, [GEN]: Genitive (marked with the suprafix), (GEN): Genitive (not marked with the suprafix), MOD: Modified, NPC: Noun-phrase clitic, [OBL]: Oblique (marked with the suprafix), UMD: Unmodified.
} 


\section{Kazuhiro Kawachi and Abebayehu Aemero Tekleselassie}

\section{The Notion of Modification in Traditional Terms in Linguistics}

When a non-polysynthetic language is dealt with, in traditional terms, modification within a noun phrase means the attribution of a property to or the restriction of the meaning of the head noun by using another syntactic constituent within that noun phrase. It is a syntactic notion, and excludes the morphological notion of affixation. Thus, an affix bound to a noun, which is not a syntactic constituent, is not regarded as a modifier. In grammatical descriptions, modifiers of nouns normally include such constituents as adjectives, numerals, adnominal demonstratives, adnominal interrogatives, (commonly, genitive) noun phrases, articles, relative clauses, adpositional phrases, and locative adverbials (Dryer 2007). In most syntactic frameworks, modifiers have to be phrasal constituents. For example, Stowell (1981) posits that every modifier must be a maximal projection of some phrasal category. Rubin (1994) proposes a model where modifiers are headed by a functional category, MOD, which takes as its complement the material denoting the content of the modification.

\section{Modification within a Noun Phrase in Sidaama}

Sidaama is a Highland East Cushitic language spoken in South Central Ethiopia (Kawachi 2007). Its case system is accusative. This language is a verb-final language whose word order is predominantly SOV, and uses suffixation (and also suprafixation for marking some grammatical cases, as discussed later). The location of high pitch in a word is usually predictable; high pitch normally falls on the penultimate vowel segments of the citation forms of most nouns and adjectives.

Modification within a noun phrase in Sidaama usually concerns whether or not a common noun is accompanied not only by an adnominal (such as an adjective, a numeral, an adnominal demonstrative, an adnominal interrogative, or a relative clause) or a genitive noun phrase, but also by the possessive pronominal suffix (1SG: -'ya, 2SG: -kki, 3SG.F: -se, 3SG.M: -si, 1PL: -nke, 2PL: -'ne, 3PL: $-n s a)$, which is bound to the noun. ${ }^{2}$ The distinction between Unmodified common nouns (those accompanied neither by a syntactic modifier nor the possessive pronominal suffix) and Modified common nouns (those accompanied by a syntactic modifier/syntactic modifiers, the possessive pronominal suffix, or both) emerges in the following seven places in the grammar of this language. ${ }^{3}$

\footnotetext{
${ }^{2}$ When the possessor of a noun is expressed by a genitive NP, the possessive pronominal suffix cannot attach to the noun.

${ }^{3}$ Note that this distinction cannot be reduced to a distinction of definiteness. Although the definite suffix -nni occurs in limited contexts (see (vi) and (vii)), Sidaama common nouns do not make a definiteness distinction morphologically in other cases (for example, in (1), the subject NP can be interpreted either as definite or indefinite). The indefiniteness of the referent of a noun phrase can be indicated by the use of an idiomatic expression where the relative clause with the verb ikk- 'to become' modifies the head common noun (in the form of ikk-i-t-ino [become-EP-3SG.F/3PL-PERF.3] for the third-person singular feminine and the third-person plural or $i k k$-ø-ino [become-3SG.M-PERF.3] for the third-person singular masculine) (e.g. ikk-ø-ino beett-i
} 


\section{Modification within a Noun Phrase in Sidaama}

\subsection{Different allomorphs of the nominative case suffix on masculine common nouns}

The nominative case suffix on masculine common nouns has different allomorphs: $-u$ for Unmodified ones, as in (1), and $-i$ for Modified ones, as in (2a) and (2b). Each allomorph replaces the final vowel of the stem (e.g. o of beetto 'child'). 4

$\begin{array}{ll}\text { beett-u } & \text { da- } \varnothing-\text {-ino. } \\ \text { child-NOM.M.UMD } & \text { come-3SG.M-PERF.3 }\end{array}$

'The boy came.'

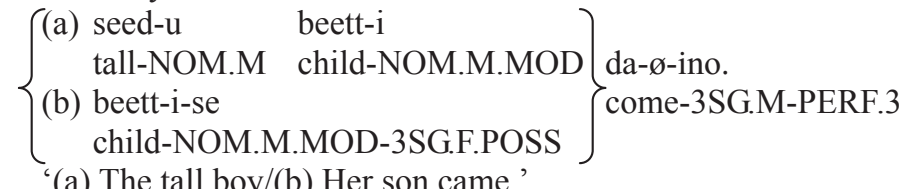

\subsection{Different allomorphs of the genitive case suffix on common nouns}

The genitive case suffix has two different sets of allomorphs, which are distinctively used for Unmodified common nouns (FEM: -te/MASC: $-u$ ) and Modified ones (FEM: $ø /$ MASC: $-i$ ); -te is added to the stem, whereas $-u$ and $-i$ each replace the final vowel of the stem. Examples of genitive forms of Unmodified feminine and masculine common nouns are shown in (3), and those of Modified feminine and masculine common nouns are shown in (4) and (5). As indicated in (3) (min- $\hat{u})$ and (5) (beettó-se, min-í-si), roughly speaking, the genitive forms of syntactically unmodified common nouns (Unmodified nouns as well as those having the possessive pronominal suffix but no syntactic modifier) are additionally marked with a suprafix, which is realized as high pitch on their final vowel segments (see the end of the present section for a discussion on the genitive suprafix).

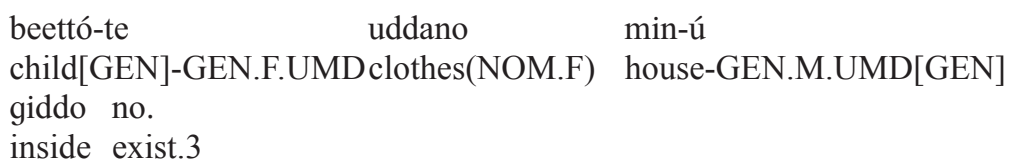


Kazuhiro Kawachi and Abebayehu Aemero Tekleselassie

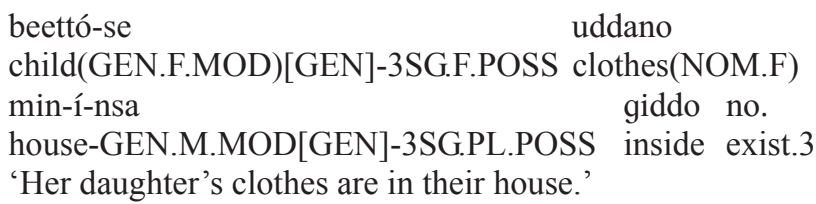

\subsection{Different allomorphs of the dative-locative case suffix on common} nouns

Different sets of allomorphs of the dative-locative case suffix are used for Unmodified common nouns (FEM: -te/MASC: $-h o$ ) and Modified ones (-ra regardless of gender). (6) contains the Unmodified forms of two nouns, one in the dative and the other one in the locative. (7) and (8) each contain the Modified forms of the same two nouns in the same two cases as in (6).

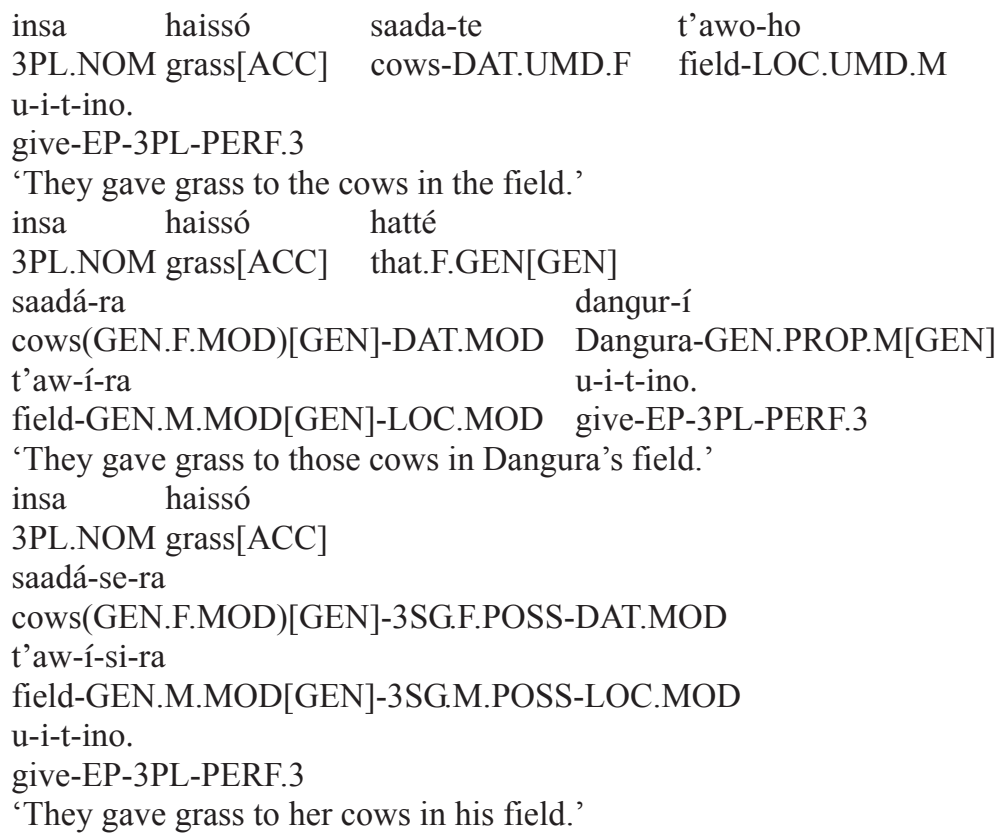

2.4. Use of the oblique case vs. the allative case for masculine common nouns that refer to the goal of motion

To express the goal of motion, for Unmodified masculine common nouns, the oblique case, which is indicated with a suprafix on the final vowel segment of a syntactically unmodified common noun, is used, as in (9), and for Modified masculine common nouns, the allative case, which is marked with the suffix -ra, 
is used, as in (10a) and (10b). ${ }^{5}$

$$
\begin{array}{ll}
\text { ise } & \text { t'awó had-d-ino. } \\
\text { 3SG.F.NOM } & \text { field[OBL]go-3SG.F-PERF.3 }
\end{array}
$$

'She went to the field.'

$$
\text { ise }
$$

3SG.F.NOM

$$
\begin{aligned}
& \text { (a) šaan-ú } \\
& \text { cabbage-GEN.M.UMD[GEN] field-GEN.M.MOD[GEN]-ALL } \\
& \text { (b) t'aw-í-si-ra } \\
& \text { field-GEN.M.MOD[GEN]-3SG.M.POSS-ALL } \\
& \text { had-d-ino. }
\end{aligned}
$$$$
\text { go-3SG.F-PERF.3 }
$$

'She went (a) to the cabbage field/(b) to his field.'

\subsection{Different forms of the noun-phrase clitic starting in $t$ (FEM)/ $h$ (MASC) when bound to a predicate common noun}

The noun-phrase clitic, which attaches to a predicate common noun, takes different forms depending on whether the noun is Unmodified (FEM: $=t e / \mathrm{MASC}:=h o$ ), as in (11), or Modified (=ti), as in (12a) and (12b).

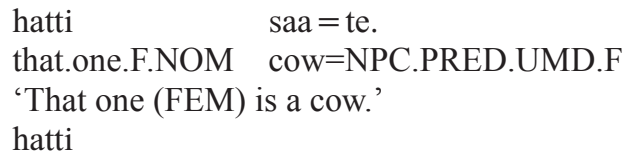

'That one (FEM) is (a) the cow that she milked/(b) his cow.'

\subsection{Use vs. non-use of the definite suffix $-n n i$ on a genitive common noun} in a predicate

When a genitive noun is followed by the noun-phrase clitic (FEM: $=t e /$ MASC: $=h o$ ) in a predicate, the definite suffix $-n n i$ has to intervene between the genitive common noun and the clitic, if the genitive common noun is Unmodified, as in (13), whereas -nni does not occur between them if the genitive common noun is Modified, as in (14a) and (14b).

\footnotetext{
${ }^{5}$ For feminine common nouns that refer to the goal of motion, oblique case forms are always used.
} 
Kazuhiro Kawachi and Abebayehu Aemero Tekleselassie

kuni $\quad \min -\mathrm{i}$

this.M.NOM house-NOM.M.MOD

beett-ú-nni $=$ ho.

child-GEN.M.UMD[GEN]-DEF=NPC.PRED.UMD.M

'This house is the boy's.'

(14) kuni min-i

this.M.NOM house-NOM.M.MOD

$\left\{\begin{array}{ll}\text { (a) busul-ú } & \text { beett-1́= ho. } \\ \text { smart-GEN.M[GEN] } & \text { child-GEN.M.MOD[GEN]=NPC.PRED.UMD.M } \\ \text { (b) beett-1́-si = ho. } & \\ \text { child-GEN.M.MOD[GEN]-3SG.M.POSS=NPC.PRED.UMD.M } \\ \text { 'This house is (a) the smart boy's/(b) his son's.' }\end{array}\right\}$

2.7. Use vs. non-use of the definite suffix $-n n i$ between a genitive masculine common noun and the noun-phrase clitic $=$ wa

Sidaama has another noun-phrase clitic, which literally means 'place'. One use of this clitic is to attach to a noun phrase referring to an object (rather than a location) to make it express a location or goal where the object is located ('at/to the place of the object'). When this clitic attaches to an Unmodified masculine common noun, the definite suffix -nni is obligatorily used between the genitive form of the noun and the clitic, as in (15). On the other hand, when this clitic attaches to a Modified masculine common noun, the definite suffix -nni may or may not occur between the genitive form of the noun and the clitic, as in (16a) and $(16 b){ }^{6}$

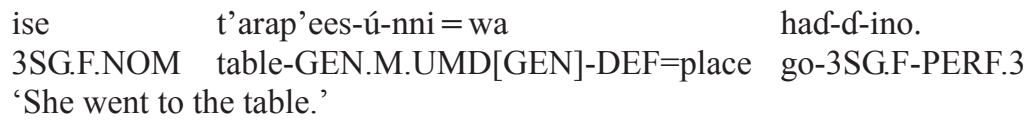

ise

3SG.F.NOM

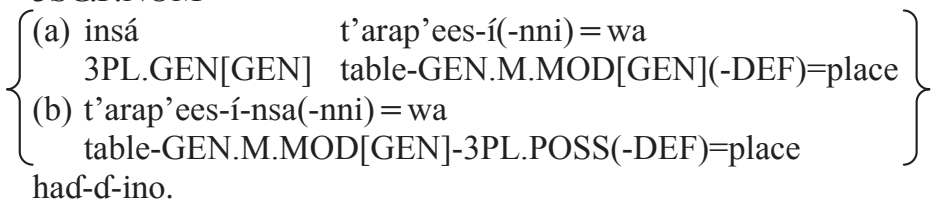
go-3SG.F-PERF.3

(a)\&(b): 'She went to their table.'

\footnotetext{
${ }^{6}$ When this clitic is used with a feminine common noun, it attaches to its genitive form either directly or with the definite suffix -nni intervening between them, regardless of whether it is Unmodified (e.g. hakk'iččo-te $=w a / h a k k$ 'iččo-nni $=w a$ 'at/to the tree') or Modified (e.g. hatté hakk'iččo $=$ wa/hatté hakk'iččo-nni= wa 'at/to that tree').
} 


\section{Modification within a Noun Phrase in Sidaama}

So far, we have described the seven cases where Sidaama makes the distinction between Unmodified and Modified common nouns. However, there are three cases where Sidaama makes a distinction in terms of (syntactic) modification in its ordinary sense, as well as (morpho-syntactic) Modification.

First, the accusative-oblique case on syntactically unmodified common nouns is marked with a suprafix, which occurs as high pitch on the final vowel segment, as in (17a) and (17b), whereas that on syntactically modified common nouns that are not accompanied by the possessive pronominal suffix has no marking, as in (18a) and (18b) (though, as in (18a), the suprafix occurs on the adnominal modifying the accusative-oblique noun). However, the accusative-oblique suprafix occurs on syntactically modified common nouns with the possessive pronominal suffix, as in (17c).

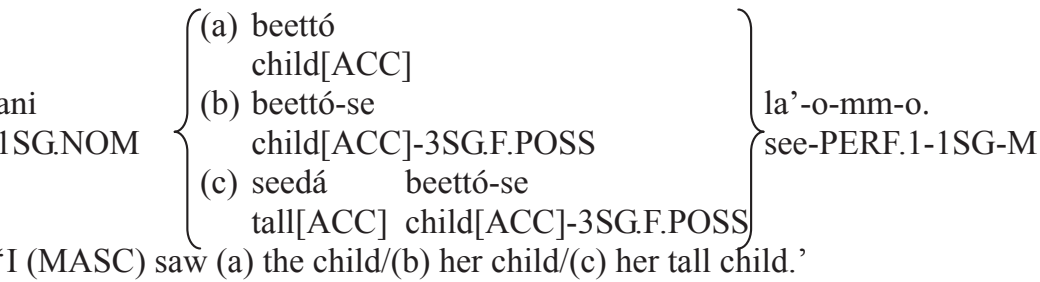

(18)

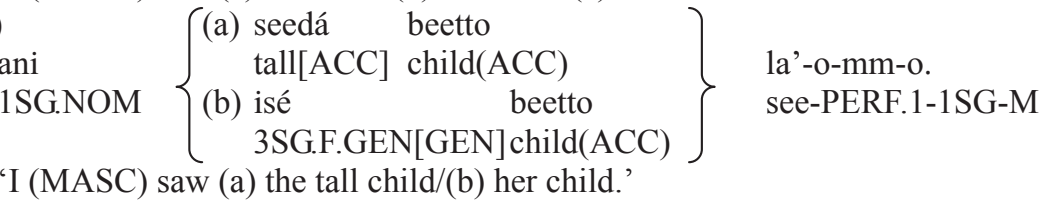

Second, similar to the accusative-oblique case suprafix, the genitive case suprafix is used for syntactically unmodified common nouns, but is not used for nouns accompanied by a syntactic modifier nor by the possessive pronominal suffix. For example, in (3), the genitive nouns, which are unmodified, are marked with the suprafix (beetto-te, min- $\hat{u}){ }^{7}$ Also in (5), the genitive nouns, which are

\footnotetext{
${ }^{7}$ High pitch also occurs on the final vowel segment of a noun stem (the final vowel of either a basic or genitive stem) when accompanied by that case suffix allomorph which is added to the stem (specifically, the dative-locative suffix -te (UMD.FEM)/-ho (UMD.MASC)/-ra (MOD, PROP), the allative suffix $-\mathrm{ra}$, which is used for Modified masculine common nouns and masculine proper nouns, and the instrumental suffix $-n n i)$, rather than replacing the final vowel of the stem. When the allomorph of the genitive suffix for an Unmodified feminine common noun -te is used, it is not clear whether high pitch on the vowel immediately preceding it is due to the use of high pitch on the stem-final noun with an adding suffix, to the genitive case marking on the unmodified noun, or to their co-occurrence. Nevertheless, the present study assumes that high pitch comes from the genitive case marking (e.g. beettó-te in (3)). When a common noun in the genitive case is modified by a syntactic modifier, the genitive suprafix does not occur on the head noun, but when it is followed by an adding suffix, high pitch occurs on the final vowel segment of its stem (e.g. t'aw-í-ra in (10a)). High pitch that does not contain the accusative-oblique or genitive suprafix is not indicated in the present study (e.g. saada-te and t'awo-ho in (6)).
} 
Kazuhiro Kawachi and Abebayehu Aemero Tekleselassie

accompanied by the possessive pronominal suffixes but are not modified by any syntactic modifier, are marked with the suprafix (beettó-se, min-í-nsa). On the other hand, in (4), the genitive nouns, which are modified by the adnominal demonstrative or the genitive pronoun, are not marked with the suprafix (hatté beetto, insá min-i $)$. However, the genitive suprafix occurs on syntactically modified common nouns with the possessive pronominal suffix (e.g. beettó-se in hatté beettó-se uddano min-ú giddo no. 'The clothes belonging to that daughter of hers are in the house.')

Third, Sidaama makes a distinction between Unmodified nouns, unmodified but Modified nouns (unmodified nouns with the possessive pronominal suffix), and modified nouns (either with or without the possessive pronominal suffix) in regard to the use of the noun-phrase clitic starting in $t$ (FEM) $/ h$ (MASC) between a relative clause and its head. If the head noun of a relative clause is Unmodified (in other words, if the noun is only modified/Modified by the relative clause), the head noun has to follow the relative clause immediately, as in (19). If the head noun of a relative clause is accompanied by the possessive pronominal suffix and is (syntactically) unmodified (in other words, if the noun is only Modified by the relative clause and the possessive pronominal suffix), the noun-phrase clitic (FEM: $=t i /$ MASC: $=h u$ when it is in the nominative case or when the head is a predicate; FEM: $=t a /$ MASC: $=h a$ when in the accusative case; FEM: =te/MASC: $=h u$ when in the genitive case), which agrees in case and gender with the head noun, can optionally occur between the relative clause and the head noun, as in (20). If the head noun of a relative clause is (syntactically) modified (in other words, modified by a modifier other than the relative clause), the noun-phrase clitic is required between the relative clause and the head noun, as in (21).

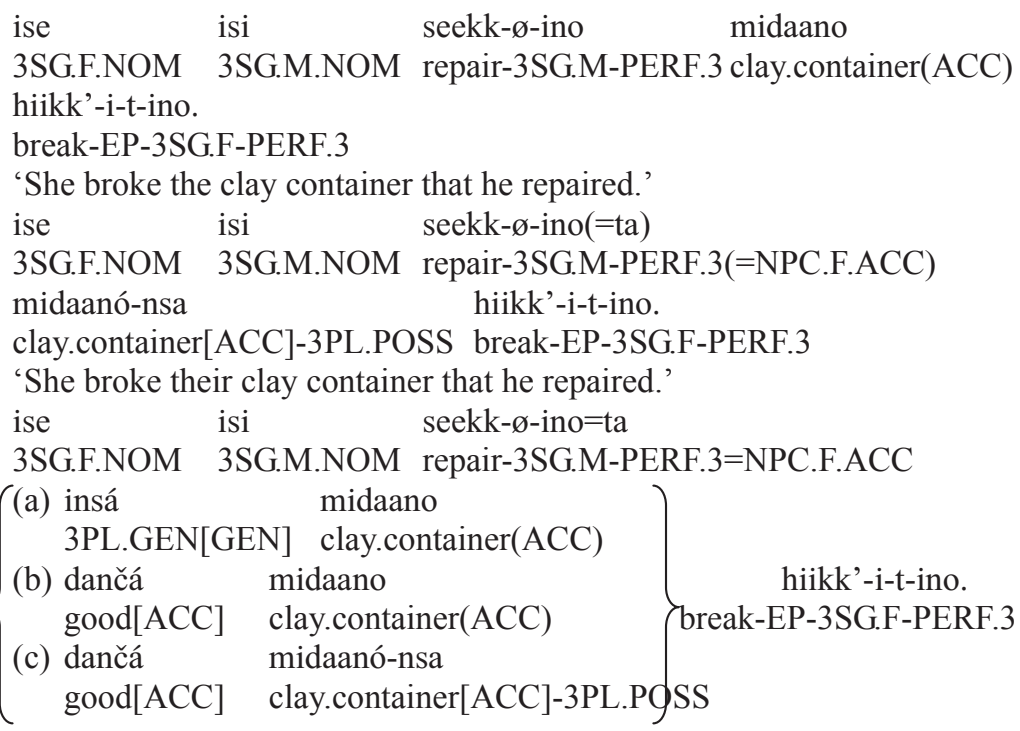




\section{Modification within a Noun Phrase in Sidaama}

(a) 'She broke their clay container that he repaired.'

(b) 'She broke the good clay container that he repaired.'

(c) 'She broke their good clay container that he repaired.'

Therefore, even within Sidaama, the notion of Modification is not exclusively the criterion for the distinction made in a noun phrase. It makes the Modification distinction in the first seven cases outlined above, while it makes the distinction in terms of both Modification and modification in the last three cases.

\section{Differences from Constructions in Other Languages}

There are two grammatical phenomena in other languages to which the modification of a common noun seems to be relevant. One is the construct state (status constructus) in Semitic languages, which are, though distantly, related to Sidaama, and the other is the Ezafe construction in Iranian languages. This section examines whether any of these constructions makes a distinction similar to the one made by Sidaama noun phrases. Notice that the question asked here is not what level of a grammatical model (e.g. in, prior to, or subsequent to the syntax) these phenomena should be analyzed as occurring, as is the focus of interest to many investigators of them (e.g. Borer 1988, 1996, Ghomesi 1997), but rather whether the modification within a noun phrase that is relevant to any of the phenomena is purely syntactic, or morphological as well as syntactic.

\subsection{Construct state in Semitic languages (e.g. Borer 1988, 1996, Benmamoun 2005)}

The construct state, which is a nominal complex found in Semitic languages, is a syntactic phrase, though it constitutes a prosodic unit and behaves as a phonological word. It shows some properties concerning syntactic modification, but the Modification distinction in Sidaama is relevant to none of them. For example, the construct state in Arabic exhibits characteristics such as the following (e.g. Benmamoun 2005). First, the (in)definiteness of the noun phrase is only marked by its last genitive noun, but is not marked by any other noun in it, as in (22a) and (22b).

\section{Arabic}

$\begin{array}{llll}\text { kitāb-u } & \text { bn-i } & \text { 'amm-i } & \text { șadīq-i } \\ \text { book-NOM } & \text { son-GEN } & \text { uncle-GEN } & \text { friend-GEN }\end{array}\left\{\begin{array}{l}\text { (a) ț-țālib-i } \\ \text { DEF-student-GEN } \\ \text { (b) țālib-in } \\ \text { student-GEN.INDEF }\end{array}\right\}$

(a) 'the book of the son of the uncle of the friend of the student'

(b) 'a book of a son of an uncle of a friend of a student' (Benmamoun 2005:478)

Thus, when a construct state noun phrase is made up of only two nouns, it has (in)definiteness marking on its second noun, but not on its first noun. Second, an adjective modifying one of the nouns in a construct state noun phrase has to occur 
Kazuhiro Kawachi and Abebayehu Aemero Tekleselassie

after the last noun regardless of which noun it modifies, as in(23a) and(23b). (Note that the adjective has to agree with the noun that it modifies in case, number, gender, and definiteness.)

(23) Arabic

$\begin{array}{lll}\text { (a) kitāb-u } & \text { t-țālib-i } & \text { 1-jadīd-u } \\ \text { book-NOM } & \text { DEF-student-GEN } & \text { DEF-new-NOM }\end{array}$ 'the new book of the student'

(b) gilāf-u kitāb-i t-tạlib-i l-jadīd-i

cover-NOM book-GENDEF-student-GEN DEF-new-GEN

'the cover of the new student's book' (Benmamoun 2005:478)

Thus, the modification relevant to the construct state in Arabic is syntactic, and it has nothing to do with Modification. (See also e.g. Borer 1988, 1996 for a description of the construct state in Hebrew, which also concerns modification rather than Modification.)

\subsection{Ezafe construction in Iranian languages (e.g. Ghomesi 1997, 2006, Samvelian 1983, 2007)}

In the Ezafe construction in Persian, modification is marked with the Ezafe enclitic $-(y) e$ on the head noun (or modified noun) and all modifiers other than the last one, as in (24a)-(24c). Here, modifiers of a noun include post-nominal modifiers such as attributive nouns, adjectival phrases, prepositional phrases, and possessor noun phrases, but do not include any pre-nominal modifier (specifically, demonstratives, quantifiers, numerals, and superlative adjectives), relative clauses, or the possessive pronominal enclitic.

\section{(24) Persian}
(a) lebâs-e zibâ
dress-EZ beautiful
'beautiful dress'
(b) lebâs-e maryam
dress-EZ Maryam
'Maryam's dress'
(c) lebâs-e arusi-e zibâ-ye bi âstin-e maryam dress-EZ wedding-EZ beautiful-EZ without sleeve-EZ Maryam 'Maryam's beautiful wedding dress without sleeves' (Samvelian 2007:608)

Because the possessive pronominal enclitic does not count as a noun modifier, when it attaches to a noun without any modifier, the Ezafe marking does not occur, as in $(25 \mathrm{a})^{8}$. When the possessive pronominal enclitic is used for a modified noun, it attaches to the final modifier, and the Ezafe enclitic occurs on the head noun and all modifiers except the final modifier, as in(25b) and(25c).

\footnotetext{
${ }^{8}$ When the possessor is expressed with an independent pronoun, the Ezafe marking occurs on the head noun and all other modifiers (Ghomeshi 2006:722) (e.g. ketâb-e mam [book-EZ 1SG] 'my book').
} 


\section{Modification within a Noun Phrase in Sidaama}

(25) Persian

(a) ketâb-am book-1SG.POSS 'my book' (b) lebâs-e sefid-e bi dress-EZ white-EZ without sleeve-1SG.POSS 'my white dress without sleeves' (Samvelian 2007:621)

(c) ketâb-e barâdar-e dust-e xâhar-am book-EZ brother-EZfriend-EZ sister-1SG.POSS 'the book of the brother of the friend of my sister' (Samvelian 1983:59)

Thus, the modification distinction made in the Persian Ezafe construction is also syntactic.

\section{Conclusion}

As shown in section 3, in Sidaama, a distinction within a noun phrase is made in terms of Modification in seven cases. On the other hand, there are also three cases where the distinction is both syntactic and morphological. Therefore, the notion of Modification/modification is not always consistent even in Sidaama.

There does not seem to be any other language that makes a Modification distinction like Sidaama. As seen in section 4, both the construct state in Semitic languages and the Ezafe construction in Iranian languages are sensitive to the modification of a noun, but they are syntactically defined, and do not include affixation.

One might be tempted to resort to the notion of headedness, rather than Modification, to describe the Modification distinction in Sidaama, but this also creates some fundamental problems. First of all, the notion of headedness is also usually used for syntactic dependency. For example, Nichols (1986), who conducted cross-linguistic studies of morphological marking of syntactic relations, explicitly states that "syntactic relations are absolutely independent of the morphology (or other means) that signal them" (p.57). ${ }^{9}$ Second, the notion of the heads of noun phrases is controversial, as pointed out by Dryer (2004).

In conclusion, the notion of modification is not universal as traditionally assumed, and needs to be expanded to include morphological affixation in addi-

\footnotetext{
9 In Nichols's analysis, most of the phenomena in Sidaama involving Modification would be treated as instances of double-marking. On one hand, the dependent bears some marking in most cases. Adnominals such as adjectives, numerals, adnominal demonstratives, and adnominal interrogatives agree with the head noun in case and gender, as in (2a), (4), (7), (13), and (14a). Genitive NPs mark possession with the genitive suffix on themselves, as in (4), (16a), and (16b). Relativization is formed by means of gapping or pronominal retention, either of which can be treated as dependent-marking. On the other hand, the head noun is marked as having a dependent whenever it is modified by a syntactic modifier, as in (i)-(vii). Thus, these can be regarded as double-marking examples. However, all the Sidaama phenomena involving Modification cannot be double-marking of syntactic relations in the following respects. First, marking of possession with the possessive pronominal suffix is not dependent-marking. Second, (viii) does not show any head-marking; relativization can be formed by gapping, which is an instance of dependent-marking, but the existence of a dependent of the head noun other than the relative clause is also marked on the dependent, specifically on the verb at the end of the relative clause.
} 
Kazuhiro Kawachi and Abebayehu Aemero Tekleselassie

tion to syntactic phenomena in order to account for the distinction made by common nouns at least in Sidaama by means of this term.

\section{References}

Benmamoun, Elabbas. 2005. The Construct State. In K. Versteegh, ed., Encyclopedia of Arabic Language and Linguistics, 477-482. Leiden, the Netherlands: Brill.

Borer, Hagit. 1988. On the Parallelism between Compounds and Constructs. Yearbook of Morphology, 1:45-66.

Borer, Hagit. 1996. The Construct in Review. In I. Lecarme, J. Lowenstamm and U. Shlonsky, eds. Studies in Afroasiatic Grammar: Papers from the Second Conference on Afroasiatic Languages, Sophia Antipolis, 1994, 30-61. The Hague: Holland Academic Graphics.

Dryer, Matthew S. 2004. Noun Phrases without Nouns. Functions of Language, 11(1):43-76.

Dryer, Matthew S. 2007. Noun Phrase Structure. In T. Shopen, ed., Language Typology and Syntactic Description, Volume 2: Complex Constructions, Second Edition, 151-205. Cambridge University Press.

Ghomesi, Jila. 1997. Non-Projecting Nouns and the Ezafe Construction in Persian. Natural Language and Linguistic Theory, 15:729-788.

Ghomeshi, Jila. 2006. NP-Anaphora and Focused Possessors in Parallel Architecture. Linguistics, 44(4):721-748.

Kawachi, Kazuhiro. 2007. A Grammar of Sidaama (Sidamo), a Cushitic Language of Ethiopia. Ph.D. diss., University at Buffalo, State University of New York.

Nichols, Johanna. 1986. Head-marking and Dependent-marking Grammar. Language, 62(1):56-119.

Rubin, Edward J. 1994. Modification: a Syntactic Analysis and its Consequences. Ph.D. diss., Cornell University.

Samvelian, Pollet. 1983. Origins of Phrasal Categories in Persian: an X-bar Analysis. Ph.D. diss., University of California, Los Angeles.

Samvelian, Pollet. 2007. A (Phrasal) Affix Analysis of the Persian Ezafe. Journal of Linguistics, 43:605-645.

Stowell, Timothy Angus. 1981. Origins of Phrase Structure. Ph.D. diss., Massachusetts Institute of Technology.

Kazuhiro Kawachi

Research Institute for Languages and Cultures Meiji Gakuin University of Asia and Africa,

Tokyo University of Foreign Studies

1518 Kamikurata-cho,

3-11-1 Asahi-cho, Fuchu-shi, Tokyo 183-8534

Totsuka-ku, Yokohama-shi

Kanagawa 244-8539 Japan

kazuhirokawachi@gmail.com,kazuhirokawachi@hotmail.com 